\title{
LOTE ECONÔMICO DE COMPRA NA INDÚSTRIA DE COMPENSADO DA REGIÃO METROPOLITANA DE CURITIBA
}

\author{
Marilene Bronoski ${ }^{1}$, Dimas Agostinho da Silva ${ }^{2}$, Roberto Rochadelli ${ }^{3}$ \\ ${ }^{1}$ Eng. Civil e Administradora, Dra ., UNIOESTE, Guarapuava, Paraná, Brasil - marilene.bronoski@gmail.com \\ ${ }^{2}$ Eng. Florestal, Dr., Depto. de Engenharia e Tecnologia Florestal, UFPR, Curitiba, Paraná, Brasil - dimass@ufpr.br \\ ${ }^{3}$ Eng. Florestal, Dr., UFPR, Palotina, Paraná, Brasil - nashtell@ hotmail.com
}

Recebido para publicação: 09/11/2007 - Aceito para publicação: 22/08/2009

\begin{abstract}
Resumo
Considerando o equilíbrio entre os custos de manutenção de estoques e o de preparação de pedidos de compra, este artigo se propôs a apontar o lote econômico de aquisição do item madeira, matéria-prima da indústria de compensados, e o comparar com as quantidades atualmente praticadas em dez indústrias desse segmento. Para efeito comparativo, estratificou-se a amostra em dois grupos, considerando-se a agregação ou não de valor ao produto final. Concluiu-se que a maioria dessas empresas já pratica quantidades próximas ao lote econômico de compra cujas médias entre as quantidades reais e as calculadas são idênticas. Observou-se, também, igualdade entre as médias dos custos totais de estoque nas duas situações. Embora individualmente a variação entre as quantidades seja de até $110 \%$, a máxima variação entre os custos totais é de apenas 9\%, confirmando uma das críticas a essa técnica, ou seja, que modificações no tamanho do lote somente devam ser propostas para diferenças superiores a $50 \%$. O número mensal de pedidos entre o praticado pela amostra e o sugerido pelo LEC difere em $7 \%$. Observou-se que ambos os grupos mantêm comportamentos semelhantes quanto às variações entre a quantidade sugerida pelo LEC e a praticada. Três empresas da amostra, por apresentarem altos custos totais de estoques, são candidatas a rever o tamanho do lote, tendendo à quantidade econômica.

Palavras-chave: Logística; lote econômico de compra; custos de estoque; indústria de compensados.
\end{abstract}

\begin{abstract}
Economic lot of purchase in the plywood industry of the Metropolitan Region of Curitiba. Considering the balance between the costs of maintenance of supplies and of preparation of purchase order, this article points the economic lot of purchase of the item wooden blade, raw material of the industry of plywood and to compare with the amounts currently practiced in ten industries of this segment. For comparative effect, the sample was divided in two groups, considering the aggregation or not of value in the final item. The conclusion is that the majority of these companies already practices amounts close to the economic lot quantity witch averages between the real amounts and the calculated ones are identical. It was also observed, equality among averages of the total costs of supply in the two situations. Although individually the variation among the amounts is $110 \%$, the maximum variation between the total costs is of only $9 \%$, confirming one of critics to this technique, the modifications in the batch size only must be proposals for differences superior to $50 \%$. The monthly number of order between the practiced for the sample and the suggested for the EOQ differs in 7\%. It was observed that both the groups keep similar behaviors in relation of the variations between the amount suggested for the EOQ and the practiced. In function of rising of total costs of supplies, three companies of sample are candidates to review these amounts, tending to the economic order quantity.

Keyword: Logistic; economical order quantity; costs of supply; industry of plywood.
\end{abstract}

\section{INTRODUÇÃO}

Apesar de controvérsias na sua utilização para fins de decisão do tamanho do lote a comprar, conceitualmente o Lote Econômico de Compra (LEC) ou a Quantidade Econômica de Compra (QEC) continua tendo um importante papel na formação dos administradores, como também tem sua aplicação recomendada em casos específicos. Inicialmente proposto por Ford W. Harris, em 1913 (KUNIGAMI; OSÓRIO, 2009), a opção pelo lote econômico de compra ou tamanho ótimo de produção para itens 
produzidos internamente, incluído na maioria dos softwares de gestão de estoque, leva em conta os custos totais de estoque, composto por quatro parcelas: 1) os custos de manutenção do estoque ou custos diretamente proporcionais ao estoque; 2) os custos de pedir (ou preparar) considerados inversamente proporcionais ao estoque; 3) os custos independentes, que não são influenciados pelo volume dos estoques; 4) o próprio custo de aquisição do item (HARRIS, 1990; MARTINS; ALT, 2006). A Região Metropolitana de Curitiba detém o maior polo madeireiro do Estado do Paraná, onde se inclui o segmento de compensados, que se caracterizam por manter grande volume de matéria-prima advinda da região Sul, extraído de florestas plantadas, e, em maior parte, das regiões Norte e Centro-Oeste, através de florestas tropicais nativas.

Este trabalho se propõe a estimar o lote econômico de compra (LEC) do item lâmina de madeira, comparar o LEC com o efetivamente praticado por essas empresas, e quantificar o custo total de estoque em ambas as situações.

\section{REVISÃO BIBLIOGRÁFICA}

O estoque na visão financeira é definido por Gitman (1997) como os ativos circulantes para o funcionamento dos processos de produção e vendas, e que representam um investimento significativo para as empresas. Fundamental para dar conta do ciclo operacional e financeiro, fica clara a importância de se administrar eficientemente esses bens, o que significa girá-los rapidamente, minimizar seu custo e mantê-los em nível suficiente para atender às necessidades da empresa e dos clientes, ou seja, compatibilizar a liquidez com a rentabilidade.

Embora a atenção maior aos estoques no Brasil já conte com quase duas décadas, em decorrência de alguns fatores, entre os quais a redução das taxas de inflação, o surgimento de sistemas computadorizados de gestão empresarial e o aumento da competição, poucos estudos sobre gestão de estoques referentes ao ramo madeireiro estão disponíveis - o que dizer então sobre o segmento de compensados, mesmo em outros países. Para tanto, utilizaram-se alguns dados levantados em outras atividades empresariais e informações gerais sobre o assunto, que podem servir, respeitando-se as diferenças e particularidades de cada um deles e dos itens estudados, de comparação e base para novos estudos.

Em hospitais norte-americanos, por exemplo, a aplicação do LEC é preferida por mais da metade dos administradores, correspondendo a 54,8\% das técnicas de gestão de estoques mais adotadas, fato apontado por Wanke (2004), conforme tabela 1:

Tabela 1. Técnicas de gestão de estoques em hospitais norte-americanos.

Table 1. Techniques of management of supplies in North American hospitals.

\begin{tabular}{lc}
\hline Técnicas de gestão de estoques & Grau de adoção \\
\hline Sistema de Reposição Contínua ou Sistema de Ponto de Pedido & $92,9 \%$ \\
Classificação ABC & $61,9 \%$ \\
Lote Econômico de Compra & $54,8 \%$ \\
MRP (Materials Requirements Planning) & $28,6 \%$ \\
Ressuprimento JIT (Just-in-time) & $28,6 \%$ \\
Duas Gavetas & $4,8 \%$ \\
\hline Fonte: Wanke (2004), modificado pelos autores.
\end{tabular}

Ainda no setor de saúde, Garcia et al. (2009), ao estudarem dez itens de estoque de baixo giro em farmácias hospitalares e convencionais da Região Metropolitana de Campinas através da filosofia de LEC, observaram um elevado estoque médio desses estabelecimentos em função do tamanho do lote praticado, com custos, comparativamente a aquisições nas quantidades econômicas, seis vezes superiores nas farmácias hospitalares e quatro vezes nas convencionais.

Outra pesquisa realizada por Corrêa; Dias (1998) em seis grandes empresas brasileiras quanto ao volume de estoques de peças sobressalentes, indica que elas não utilizam ou subutilizam os modelos tradicionalmente encontrados na literatura. Apontam, também, que o motivo para isso está no fato dos seus gestores os desconhecerem ou não os dominarem suficientemente bem para utilizá-los ou 
considerarem o seu uso após uma avaliação, preferindo os ditos modelos intuitivos, baseando-se nas suas próprias impressões e em opiniões dos usuários.

A INTERNATIONAL MANUFATURING STRATEGY SURVEY (IMSS), em pesquisa realizada em vinte países, comparando-os com respeito à adoção da técnica JIT (just-in-time), aponta que as empresas japonesas são as que mais se aproximam desse modelo, com 11 dias de cobertura de estoques, seguidas pelas alemãs, com 31,8 dias. Por cobertura de estoques entende-se o período de tempo que o estoque consegue suprir as necessidades futuras sem que haja suprimento (LEVY; WEITZ, 2000). Alguns motivos apurados por Fleury; Arkader (1995) como dificuldades de previsão das necessidades de materiais, falta de padronização e descontrole de estoque justificam a alta cobertura das empresas brasileiras, que é, em média, de 41,5 dias, bem distante, portanto, das japonesas.

\section{Sistemas de gestão de estoques}

Para melhor entendimento do que é lote econômico de compra, recorremos a um dos fundamentos da gestão de estoques, que é a resposta a duas questões: quanto e quando repor os estoques. Segundo Martins; Laugeni (2000), existem dois sistemas que respondem a essas perguntas de maneira distinta: o sistema de reposição contínua e o sistema de reposição periódica.

Sistema de reposição contínua ou sistema de ponto de pedido

Esse sistema, também conhecido como sistema de estoque mínimo ou sistema de ponto de reposição, funciona basicamente da seguinte maneira: define-se o nível de estoque $\mathrm{R}$, e quando o estoque alcança essa quantidade, também chamada de ponto de pedido (PP), é emitida uma ordem de reposição na quantidade Q. Essa quantidade é fixa ao longo do tempo e responsável pelo recomeço do ciclo. A figura 1 representa a situação entre o consumo - representado pela linha inclinada - e o tempo de ressuprimento do material T, constante. Esse gráfico, pela forma que apresenta, é também conhecido como "curva dente de serra".

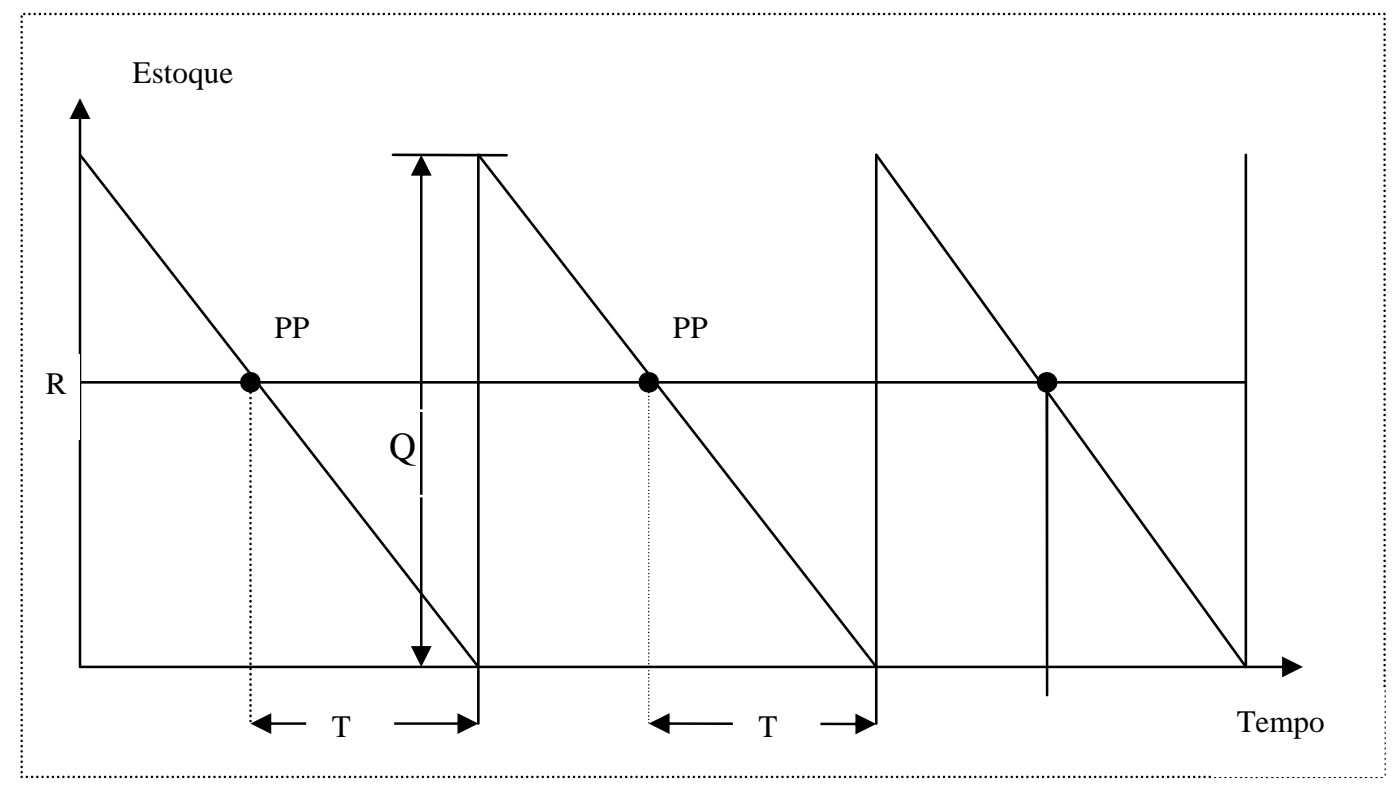

Fonte: Martins; Laugeni (2000).

Figura 1. Sistema de reposição contínua ou sistema de ponto de pedido.

Figure 1. Continuous reposition system or reposition point system.

Em caso da serem a demanda $\mathrm{D}$ e o tempo de ressuprimento (T) constantes, o ponto de pedido PP será igual a D x T. Em se tratando de demanda e tempo de ressuprimento variáveis, o cálculo do ponto de pedido será igual à demanda média no período de reposição somada ao estoque de segurança, como demonstrado na da figura 2 . 


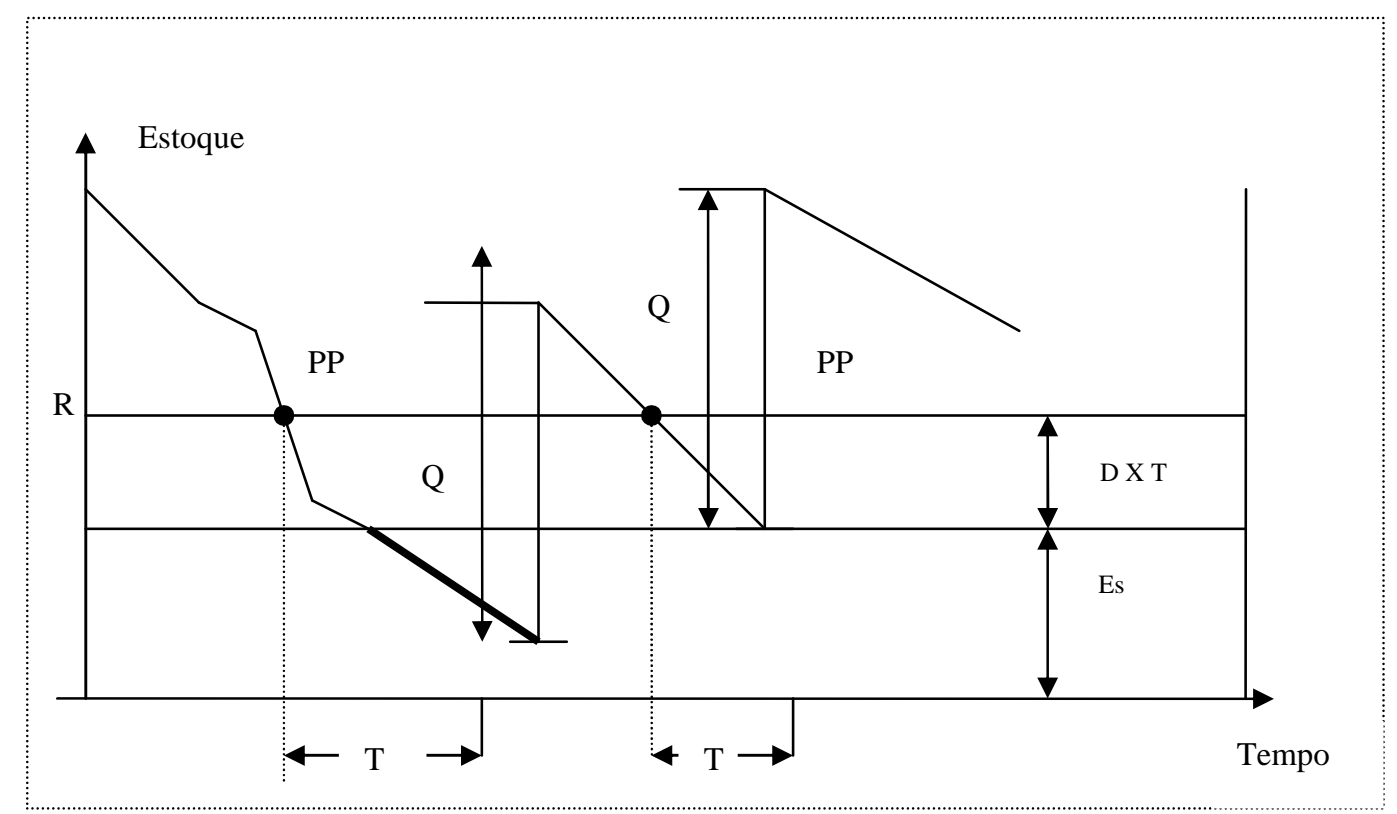

Fonte: Martins; Laugeni (2000).

Figura 2. Modelo de reposição contínua com demanda e tempo de ressuprimento variáveis.

Figure 2. Continuous reposition model with demand and resupply time variables.

A equação que define a quantidade a ser comprada quando se atinge o volume de estoque R, chamado de ponto de pedido, é:

$$
\mathrm{PP}=\mathrm{Dm} \times \mathrm{Tm}+\mathrm{Es}
$$

Em que: Dm = demanda média;

Tm = tempo de reposição médio;

Es = estoque mínimo ou de segurança.

A necessidade dos estoques de segurança apenas se dá em função das variações das demandas no período considerado e da variação do tempo para a reposição dos estoques pelos fornecedores. Essa situação é a que ocorre na grande maioria dos casos num ciclo operacional de qualquer empresa. Os estoques de segurança diminuem os riscos do não atendimento das solicitações dos clientes internos e externos. Segundo Martins; Alt (2006), utilizando-se esse modelo, o risco pode ocorrer após a emissão do pedido de compras no atingimento do ponto de pedido, quando de uma aceleração na demanda. A inconstância, portanto, nos prazos de entrega dos produtos, bem como uma dificuldade na previsão de produção e vendas forçam a manutenção de maiores volumes de estoque - estoque de segurança -, para fazer frente a essas variáveis sem interromper a produção.

Sistema de reposição periódica

Esse sistema é também chamado de sistema de estoque máximo ou sistema de intervalo padrão. Ele consiste em emitir os pedidos de compras em lotes com intervalos de tempo fixos, por exemplo, semanal, quinzenal ou mensalmente, após se fazer a verificação do nível de estoque do item (MARTINS; ALT, 2006; MARTINS; LAUGENI, 2000). Na figura 3, é ilustrado o comportamento desse sistema.

Como a demanda geralmente é variável, utiliza-se a demanda média. Da mesma forma se faz com o tempo de ressuprimento quando ele é variável. Nesse modelo, o tempo de ressuprimento T não é tão importante quanto no modelo de reposição contínua. No primeiro período IP, verifica-se a quantidade Q1 para completar o estoque máximo (Emáx). Solicita-se a reposição dessa quantidade, que é entregue depois de decorrido o tempo de reposição T1, aumentando o estoque nessa ocasião. Novamente, 
decorrido o período IP predeterminado, verifica-se a quantidade necessária Q2 para completar o estoque máximo, e o ciclo se repete (MARTINS; LAUGENI, 2000).

A expressão para calcular o estoque máximo (Emáx) é:

$$
\text { Emáx }=\text { Dm x }(\text { Tm }+ \text { IP })+\text { Es }
$$

Em que: $\mathrm{Dm}=$ demanda média do período;

Tm = tempo de reposição médio;

IP = intervalo padrão ou de revisão;

Es $=$ estoque mínimo ou de segurança.

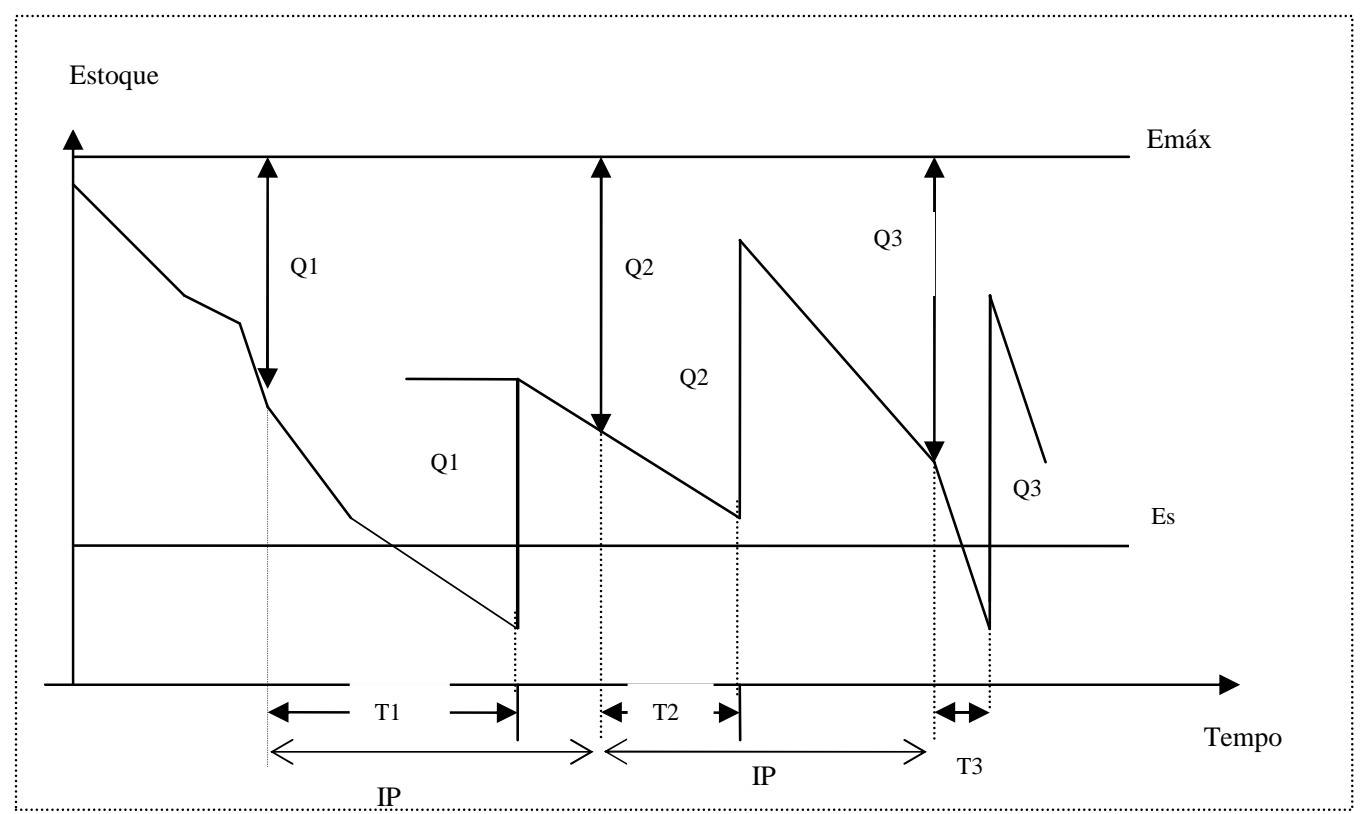

Fonte: Martins; Alt (2006).

Figura 3. Sistema de reposição periódica ou sistema de intervalo padrão.

Figure 3. Periodic reposition system or standard interval system.

Lote econômico de compra

Se o sistema de reposição periódica ou intervalo padrão responde à pergunta quanto repor? através da diferença entre o estoque máximo (Emáx) e o nível de estoque existente no instante em que é feita a revisão, o sistema de reposição contínua ou ponto de pedido define a quantidade a ser pedida, fixada previamente. Esse sistema exige o cálculo da quantidade pelo lote econômico de compra, que se baseia nas seguintes suposições, segundo Arnold (1999):

- a demanda é relativamente constante e conhecida;

- o item é produzido ou comprado em lotes e não de forma contínua;

- os custos com a preparação de pedido e os de manutenção de estoque são relativamente constantes e conhecidos;

- a reposição ocorre imediatamente e não de forma parcelada.

Na figura 1, apresentada inicialmente, é representada a configuração em que se dá essa situação.

Segundo Corrêa (1994), o LEC (lote econômico de compra), também denominado EOQ (economical order quantity), gira em torno de um ponto ideal em que a compra será mais econômica para a empresa.

Para apurá-lo, leva-se em conta apenas o aspecto quantitativo, observado pelos custos decorrentes dos estoques. Tenta-se, a partir dessa abordagem, encontrar o melhor equilíbrio entre as vantagens de manter estoque, tendo como base o comportamento de alguns custos sobre os estoques (SLACK et al., 1997; HARRIS, 1990). Enquanto alguns custos aumentam com o estoque médio, outros 
diminuem com o volume médio de estoque e outros não sofrem variação em função desse volume, o que leva a crer que exista um ponto tal que iguale esses dois primeiros custos, indicando a quantidade ótima a ser pedida.

\section{MATERIAL E MÉTODOS}

\section{Área de atuação}

A pesquisa foi realizada na Região Metropolitana de Curitiba, estado do Paraná, representada por vinte e seis municípios, considerada o maior polo madeireiro do estado, compreendendo $30 \%$ das indústrias de compensados ou um total de vinte e sete unidades empresariais (FEDERAÇÃO DAS INDÚSTRIAS DO ESTADO DO PARANÁ, 2005).

Embora a região não compreenda as maiores empresas em capacidade instalada e volume produzido, compôs-se de um universo adequado para a pesquisa, pela diversidade da matéria-prima utilizada, composta de madeira tropical (originária, principalmente, das regiões Centro-Oeste e Norte do país) e pínus e eucalipto (das regiões Sul e Sudeste), bem como pelos diferentes portes empresariais e variações no produto acabado.

\section{Design de pesquisa}

Para consecução dos objetivos pretendidos, desenvolveu-se uma pesquisa pura ou básica, que tem por meta o saber, buscando a satisfação de uma necessidade intelectual pelo conhecimento, juntamente como uma pesquisa aplicada, cuja finalidade, segundo Cervo; Bervian (1996), é contribuir para fins práticos mais ou menos imediatos, procurando soluções para problemas concretos.

Pelo tema específico ser pouco conhecido, a pesquisa foi do tipo exploratória, cuja finalidade principal, de acordo com Demo (1995), é a de desenvolver e esclarecer conceitos e ideias para a formulação de problemas mais precisos para estudos posteriores. Foi realizada em forma de senso, com todas as empresas componentes do universo sendo pesquisadas.

Pelas características do trabalho pretendido, a pesquisa foi de natureza descritiva, com uma abordagem metodológica quantitativa e qualitativa, uma vez que se permite analisar aspectos objetivos. $\mathrm{O}$ nível de análise foi o organizacional, dirigido às empresas produtoras de compensados na Região Metropolitana de Curitiba.

\section{Coleta de dados}

No processo investigatório - busca de dados necessários ao estudo, ou seja, custos de manutenção de estoque, de pedido, demanda e preço médio dos itens lâmina de madeira e sarrafo, formas predominante da matéria-prima do segmento, classificado como pertencente à classe $\mathrm{A}$-, foram utilizadas fontes primárias coletadas diretamente nas unidades empresariais, através de entrevista orientada por questionário estruturado e semiestruturado, contendo questões abertas, fechadas e de múltipla escolha, aliada a observação não-participante. Fontes secundárias também foram utilizadas, através da análise de documentos internos às organizações, como guias de transporte de madeira, catálogos de produtos, tabelas de preços, ordens de produção e notas fiscais de compra, entre outros. As visitas para a realização da pesquisa aconteceram após agendamento prévio, durante os meses de junho a dezembro de 2006. Todas as empresas foram contactadas, obtendo-se o atendimento pleno das questões por dez das empresas entrevistadas (ou 55\% do universo).

\section{Tipo de amostragem}

Em que pesem as grandes diferenças entre as empresas componentes da amostra, tanto nos aspectos físicos, como porte, capacidade produtiva, tipos de produtos fabricados, mercado consumidor e faturamento, entre outros, quanto nos gerenciais, como estratégias mercadológicas e forma de utilização dos recursos, para efeito de análise comparativa optou-se por subdividir a amostra em dois outros grupos, levando-se em conta o produto final. A tabela 2 demonstra essa distribuição.

Entendem-se como compensados de maior valor agregado materiais que foram remanufaturados, propiciando um grau superior de produto acabado, como a mudança de forma, espessura, perfil ou outras características físicas, ou seja, a partir do contraplacado são originadas vigas, 
molduras, artefatos, paletes e contenedores e peças para montagem de mobiliário, entre outros (VALLUE ADDED PRODUCTS, 2007).

Por questões éticas e preservando a identidade das empresas, elas são identificadas apenas com os números de 1 a 10 .

Tabela 2. Caracterização e estratificação da amostra por produto, para fins de análise.

Table 2. Characterization and stratification of the sample by product, for analysis purposes.

\begin{tabular}{llc}
\hline Grupo & \multicolumn{1}{c}{ Caracterização } & Número de empresas \\
\hline 1 & $\begin{array}{l}\text { Empresas fabricantes de compensado, independentemente do tipo de } \\
\text { produto comercializado (AMOSTRA). }\end{array}$ & 10 \\
2 & $\begin{array}{l}\text { Empresas que fabricam e comercializam exclusivamente o painel de } \\
\text { compensado (SUBGRUPO A PARTIR DA AMOSTRA) } \\
\text { Empresas que produzem o compensado como insumo para outros produtos } \\
\text { de maior valor agregado (SUBGRUPO A PARTIR DA AMOSTRA) }\end{array}$ & 6 \\
\hline Fonte: Os autores.
\end{tabular}

\section{Limitações do estudo}

Entrevistas, quando versam sobre situações passadas, podem estar sujeitas a vieses provenientes do esquecimento e da influência do pesquisador, não expressando a realidade dos fatos na ocasião do seu acontecimento. Essa limitação foi minimizada pela condução pessoal da entrevista, que, através da observação, correções e complementações das informações, puderam ser feitas in loco. Apesar disso, em alguns casos, novos contatos foram necessários para aferição de alguns dados, por ocasião de sua análise.

É oportuno lembrar que, para o cálculo do lote econômico, utilizou-se uma estimativa de demanda média compatível com a produção atual, como recomenda a bibliografia própria, e não na realidade dessas empresas, que se encontram, atualmente, numa situação atípica em termos de produção e comercialização, por questões mercadológicas, e, consequentemente, no processo de abastecimento, reafirmando mais a importância teórica do que prática no cálculo dessa variável.

Destaque-se que os resultados encontrados baseiam-se unicamente nas informações verbais fornecidas pelos responsáveis, uma vez que os dados referentes a custos logísticos, na sua maioria, não são registrados pela contabilidade. Aliado a isso, o próprio levantamento dos custos de carregamento e de pedido, conforme Martins; Alt (2006), é de difícil rateio, podendo ser entendendido como mais uma limitação no uso dessa técnica.

\section{Variáveis consideradas}

Consideraram-se as variáveis abaixo descritas, cujos conceitos e apuração são os sugeridos, com pequenas modificações, pelos autores Francischini; Gurgel (2002); Arnold (1999) e Martins; Alt (2006). Os dados quantitativos, por questões práticas, se referem à média mensal.

Custos diretamente proporcionais aos estoques

Também conhecidos como custos de manutenção, de estocagem ou de carregamento de estoque, são os que aumentam com o aumento do estoque médio, num determinado período de tempo. A unidade dimensional é unidade monetária/(unidade física) X (unidade de tempo), e é representada por Cc.

\section{Capital (Ccap)}

Os custos de carregamento $(\mathrm{Cc})$ considerados são:

Nesse item foram considerados os custos inerentes ao capital aplicado em um metro cúbico de lâmina de madeira (laminada ou torneada), ou seja, os juros médios que seriam recebidos em aplicações financeiras ou rentabilidade mínima exigidos pela empresa ou ainda através de empréstimo. Utilizou-se, para a remuneração do capital, a taxa média de juros Selic referente ao ano da pesquisa (2006), que foi de 13,19\% (BANCO CENTRAL DO BRASIL, 2007), a partir das informações fornecidas pelos entrevistados, referentes ao volume médio mensal estocado e o preço do metro cúbico de matéria-prima (lâminas e sarrafos) na ocasião da pesquisa.

Armazenagem $(\mathrm{Ca})$

Identificados como $\mathrm{Ca}$, foram considerados os custos decorrentes não apenas de armazenagem, mas também os de seguro relativo ao estoque, manuseio (incluindo mão de obra, equipamentos e 
embalagem), impostos (predial, alfandegários e outros), despesas diversas decorrentes da existência dos estoques (material de escritório, luz, telefone etc.), perdas e obsolescência referentes à estocagem da madeira (lâminas torneadas e laminadas e sarrafos). O custo de transporte (frete) foi considerado nessa categoria, visto que incide sobre o volume transportado, portanto proporcional ao estoque médio. $\mathrm{O}$ aluguel (ocupação física do estoque), quando incidente sobre área ou prédio exclusivo para armazenagem do insumo madeira, também faz parte desse fator. Para efeito de cálculo, utilizou-se o valor do metro quadrado médio para locação, através de tabelas do Sindicato da Habitação do Paraná (SECOVI-PR, 2007), referente ao ano de 2006, tanto para imóveis próprios como de terceiros.

Custos inversamente proporcionais aos estoques

Incluiu-se o custo de pedir, preparar, negociar, além do acompanhamento e a recepção do pedido. Foi obtido através da somatória de todos os custos administrativos e operacionais da área de compras referentes ao período considerado, dividida pelo número de pedidos feitos nesse período $(\mathrm{N})$. A unidade dimensional é unidade monetária/pedido ou unidade monetária/tempo, representada por $\mathrm{Cp}$.

Custo total de estoque

Levantado a partir da somatória de todas as parcelas de custos incidentes sobre os estoques médios acrescido do valor médio adquirido do item analisado ( $\mathrm{D} \times \mathrm{P}$ ), utilizando-se a seguinte expressão:

$$
\mathrm{CTE}=(\mathrm{Ca}+\mathrm{Ccap}) \mathrm{X} \mathrm{Q} / 2+(\mathrm{Cp}) \mathrm{X} \mathrm{D} / \mathrm{Q}+\mathrm{D} \mathrm{X} \mathrm{P}
$$

Em que: $\mathrm{CTE}=$ custos totais de estoque;

$\mathrm{Ca}=$ custos de armazenagem;

Ccap = custo de capital;

$\mathrm{Q}=$ lote de compra;

$\mathrm{Cp}=$ custo de preparação ou de pedido;

$\mathrm{D}=$ demanda do período;

$\mathrm{P}=$ preço unitário do item.

Cálculo do lote econômico de compra

A expressão do LEC foi obtida pela derivação da equação do custo total de estoque (CTE), igualando-se a zero:

$$
\mathrm{LEC}=\mathrm{QLEC}=(2 \mathrm{Cp} * \mathrm{D} /(\mathrm{Cc}))^{1 / 2}
$$

Em que: $\mathrm{QLEC}=$ quantidade econômica a ser comprada;

$\mathrm{Cp}=$ custo de preparação ou de pedido;

$\mathrm{D}=$ demanda do período determinado;

$\mathrm{Cc}=$ custo de carregamento ou de manutenção.

\section{Tratamento dos dados}

Foram utilizadas medidas estatísticas, como a média, o desvio padrão e o coeficiente de variação de algumas das variáveis. Para cálculo das medidas estatísticas para posterior análise e interpretação, utilizou-se o Programa Microsoft Office Excel, com a geração de tabelas e gráficos ilustrativos.

\section{RESULTADOS E DISCUSSÃO}

O lote econômico de compra (LEC) apurado do insumo madeira, de acordo com a Equação 4 apresentada, mostra que algumas empresas já praticam quantidades, se não iguais, próximas à econômica, como demonstrado na figura 4 e tabela 3 .

As maiores distorções aparecem nas empresas de números 1, 4, 8, e, de forma mais forte, na empresa de número 10 , neste caso com uma variação de $110 \%$, ou seja, adquire essa matéria-prima em lotes, aproximadamente, duas vezes o recomendado como econômico.

A empresa de número 2 pertencente ao Grupo 3, compra lotes econômicos, seguida de perto pelas empresas de números 6 e 7, pertencentes ao Grupo 2, com variações de 2,0\% e 4,0\% entre os lotes 
praticados e sugeridos, respectivamente. A média do lote praticado pela amostra é igual à do lote econômico apurado, ou quarenta e três metros cúbicos de madeira por pedido.

Seis empresas (de números $1,3,4,5,6,7$ ) ou $60 \%$ do total praticam compras em lotes menores, e outras três (de números 8,9 e 10) ou $30 \%$ do total compram em quantidades superiores à sugerida pelo LEC.

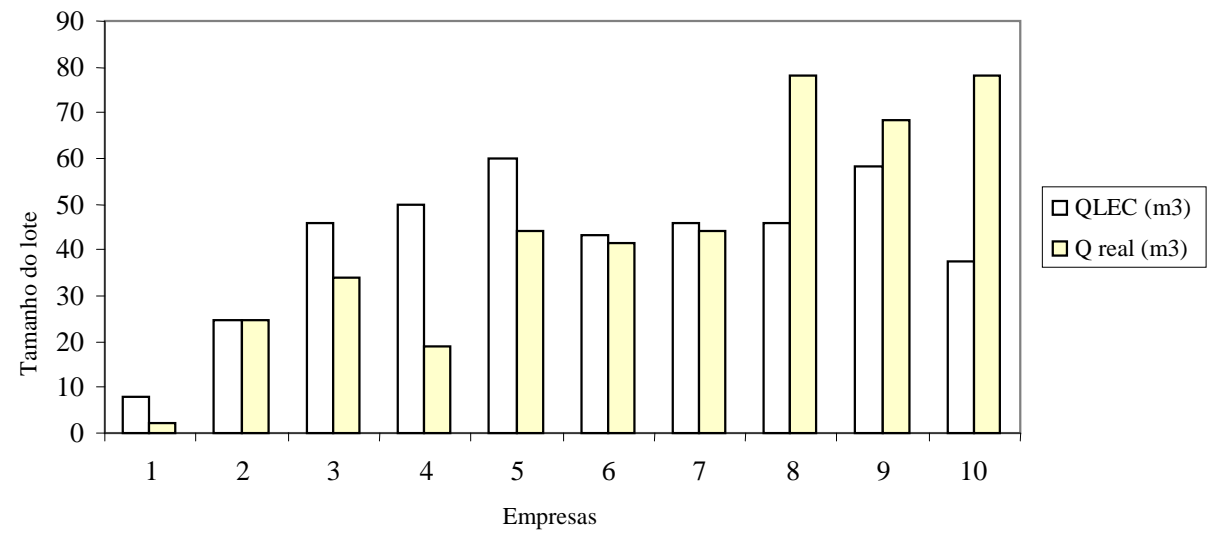

Fonte: Os autores.

Figura 4. Comparação entre o lote econômico de compra (LEC) e o lote praticado (Qreal), por empresa pertencentes ao Grupo 1.

Figure 4. Comparison between the economical order quantity (EOQ) and the real quantity (Qreal), by company belonging to the Group I.

Tabela 3. Variação entre o lote real (Qreal) e o econômico de compra (LEC), Grupo 1.

Table 3. Variation between real quantity (Qreal) and the economical order quantity (EOQ) in Group 1.

\begin{tabular}{lccc}
\hline Empresas & $\begin{array}{c}\text { Lote econômico de compra }(\mathbf{L E C}) \\
\left(\mathbf{m}^{\mathbf{3}}\right)\end{array}$ & $\begin{array}{c}\text { Lote praticado (Qreal) } \\
\left(\mathbf{m}^{\mathbf{3}}\right)\end{array}$ & $\begin{array}{c}\text { Variação entre o lote praticado e } \\
\text { o lote econômico }\end{array}$ \\
\hline 1 & 8 & 2 & $-75,0$ \\
$\mathbf{2}$ & $\mathbf{2 5}$ & $\mathbf{2 5}$ & $\mathbf{0 , 0}$ \\
3 & 46 & 34 & $-26,0$ \\
4 & 50 & 19 & $-62,0$ \\
5 & 60 & 44 & $-27,0$ \\
6 & 43 & 42 & $-2,0$ \\
7 & 46 & 44 & $-4,0$ \\
8 & 46 & 78 & 70,0 \\
9 & 58 & 68 & 17,0 \\
10 & 37 & 78 & 110,0 \\
\hline Médias & 43 & 43 & 0,0 \\
\hline
\end{tabular}

Fonte: Os autores.

A figura 5 e a tabela 4 mostram o comportamento dos custos totais de estoque (em moeda americana) e o lote (em metros cúbicos), nas duas situações.

Fazendo-se um comparativo entre as médias dos custos totais decorrentes do lote econômico e o resultante do lote atualmente praticado pelas empresas, percebe-se uma diferença pouco representativa em valor e coincidente em percentual. 


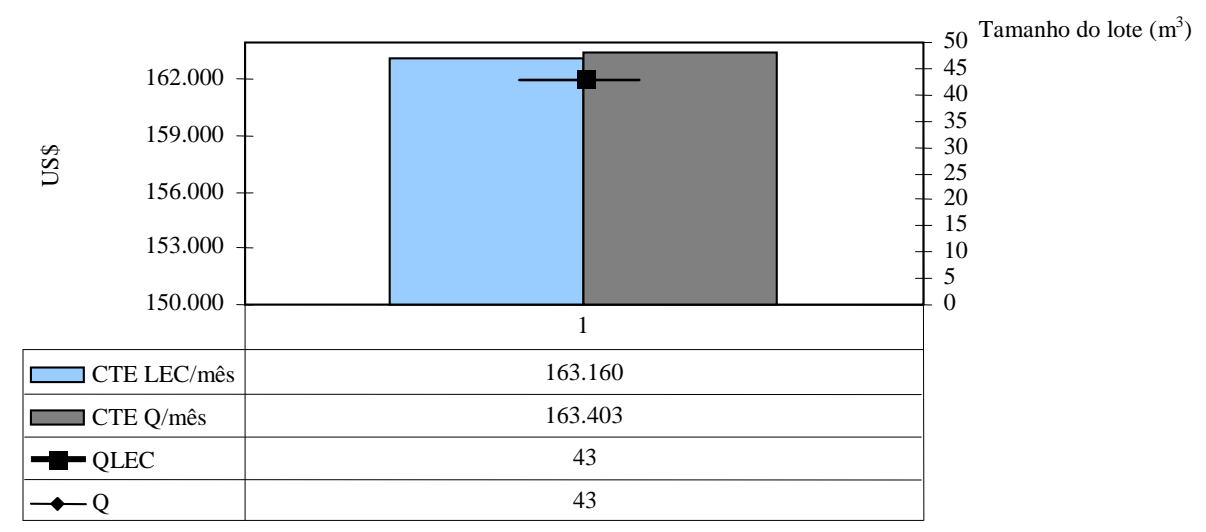

Fonte: Martins; Laugeni (2000).

Figura 5. Comparativo entre as médias do lote econômico de compra (LEC) $\left(\mathrm{m}^{3}\right)$, custo total de estoque (CTE) relativo ao LEC (US\$/mês), lote praticado (Q real) $\left(\mathrm{m}^{3}\right)$ e o custo total de estoque (CTE) relativo ao lote praticado (Qreal) (US\$/mês).

Figure 5. Comparative degree between the averages of the economical order quantity (EOQ) $\left(\mathrm{m}^{3}\right)$, total cost of supply (CTE) relative to EOQ (US\$/mês), quantity practised (real Q) $\left(\mathrm{m}^{3}\right)$ and the total cost of supply (CTE) relative to the practiced quantity (Qreal) (US\$/mês).

Tabela 4. Comparativo entre as variáveis decorrentes do lote econômico de compra (LEC) e o efetivamente praticado pelas empresas (Qreal).

Table 4. Comparative degree between the decurrent variables of the economical order quantity (EOQ) and effectively practiced by the companies (Qreal).

\begin{tabular}{lccccccc}
\hline & \multicolumn{2}{c}{ Lote econômico de compra } & \multicolumn{2}{c}{ Lote de compra praticado } & Relação \\
\cline { 2 - 7 } Empresas & $\begin{array}{c}\text { Lote } \\
\text { econômico } \\
\text { de compra } \\
\left(\mathbf{m}^{\mathbf{3}}\right)\end{array}$ & $\begin{array}{c}\text { Número } \\
\text { de } \\
\text { pedidos } \\
(\mathbf{N})(\mathbf{m e ̂ s})\end{array}$ & $\begin{array}{c}\text { Custo total } \\
\text { de estoque } \\
\text { /mês (US\$) }\end{array}$ & $\begin{array}{c}\text { Lote } \\
\text { praticado } \\
\left(\mathbf{m}^{\mathbf{3}}\right)\end{array}$ & $\begin{array}{c}\text { Número } \\
\text { de } \\
\text { pedidos } \\
\text { (mês) }\end{array}$ & $\begin{array}{c}\text { Custo total } \\
\text { de estoque } \\
\text { /mês (US\$) }\end{array}$ & $\begin{array}{c}\text { costre os } \\
\text { custos } \\
\text { totais }\end{array}$ \\
\hline 1 & 8 & 4 & $7.101,56$ & 2 & 15 & $7.778,81$ & 0,91 \\
2 & 25 & 4 & $37.905,87$ & 25 & 4 & $37.905,87$ & 1,00 \\
3 & 46 & 13 & $90.795,45$ & 34 & 18 & $90.866,30$ & 1,00 \\
4 & 50 & 9 & $73.510,45$ & 19 & 24 & $74.054,50$ & 0,99 \\
5 & 60 & 18 & $230.315,44$ & 44 & 24 & $230.434,43$ & 1,00 \\
6 & 43 & 14 & $268.402,54$ & 42 & 15 & $268.404,31$ & 1,00 \\
7 & 46 & 14 & $315.889,96$ & 44 & 15 & $315.891,47$ & 1,00 \\
8 & 46 & 22 & $391.144,63$ & 78 & 13 & $391.788,86$ & 1,00 \\
9 & 58 & 18 & $154.572,25$ & 68 & 15 & $154.593,87$ & 1,00 \\
10 & 37 & 8 & $61.960,29$ & 78 & 4 & $62.314,39$ & 0,99 \\
\hline Médias & 43 & 14 & $163.159,84$ & 43 & 15 & $163.403,28$ & 1,00 \\
\hline
\end{tabular}

\section{CONCLUSÕES}

Conforme os resultados obtidos, conclui-se que:

- Movidas apenas pelo empirismo, as empresas amostradas utilizam a técnica de lote econômico de compra na gestão do insumo lâmina de madeira.

- As empresas componentes da amostra já praticam a quantidade próxima ao LEC do insumo estudado.

- O lote médio de compra praticado atualmente pelas indústrias de compensado da Região Metropolitana de Curitiba corresponde exatamente à quantidade econômica média calculada. 
- Para três empresas da amostra (números 1, 4 e 10), as diferenças entre os custos totais sugerem um aprofundamento sobre a viabilidade na alteração do lote atualmente praticado, adequando-o ao LEC.

- A proximidade entre a quantidade de compra atualmente praticada e o lote econômico calculado independe do grupo ao qual a empresa pertence.

- As diferenças entre os custos totais individuais de estoque nas empresas componentes da amostra são inexpressivas em face das diferenças entre o lote praticado e o econômico calculado. Com variações de até $110 \%$ entre as quantidades (econômica e praticada), os custos totais de estoque tiveram uma variação máxima de apenas $9 \%$.

- A frequência dos pedidos nas duas situações é praticamente a mesma.

- Apesar das limitações do uso da técnica, sua maior importância está em servir de parâmetro na comparação com os lotes praticados e estimular a apuração dos custos de carregamento e de pedido, importantes para tomadas de decisão concernentes à melhoria no desempenho logístico da empresa em relação a sua gestão de estoques.

\section{REFERÊNCIAS}

ARNOL, J. R. T. Administração de materiais. São Paulo: Atlas, 1999.

BANCO CENTRAL DO BRASIL. Indicadores econômicos. Disponível em: <http://www.bcb.gov.br/pec/indeco/portal> Acesso em: 01 mar. 2007.

CERVO, A. L.; BERVIAN, P. A. Metodologia científica. 4. ed. São Paulo: Makron Books, 1996.

CORRÊA, H. L.; DIAS, G. P. P. De volta a gestão de estoques: as técnicas estão sendo usadas pelas empresas? Anais do SIMPOI, Fundação Getúlio Vargas, São Paulo: FGV, 1998.

CORRÊA, H. L.; GIANESI, I. G. N. Just in time, MRP II e OPT: um enfoque estratégico. 2. ed. São Paulo: Atlas, 1994.

DEMO, P. Metodologia científica em ciências sociais. 3. ed. revisada e ampliada. São Paulo: Atlas, 1995, p. 44.

FEDERAÇÃO DAS INDÚSTRIAS DO ESTADO DO PARANÁ. FIEP. Catálogo das Indústrias do Estado do Paraná de 2005, Curitiba, 2006.

FLEURY, P. F.; FIGUEIREDO, K. F. Logística empresarial: a perspectiva brasileira. São Paulo: Atlas, 2000. Coleção COPPEAD de Administração.

FLEURY, P. F.; ARKADER, R. Organização e desempenho em manufatura nas empresas brasileiras: um estudo comparativo internacional na indústria metal-mecânica. Relatório Coppead (1995). Universidade Federal do Rio de Janeiro. Disponível em: <http:// www.coppead.ufrj.br> Acesso em: 12 set. 2007.

GARCIA, L. C.; PEREIRA, M.; OSÓRIO, W. R. Gestão dos parâmetros de estoque: estudo de caso de itens de medicamentos em farmácias hospitalares e convencionais. Revista Gestão Industrial. Universidade Tecnológica Federal do Paraná - UTFPR, ISSN 1808-0448/v. 05, n. 01: p. 109-121, 2009.

GITMAM, L. J. Princípios de administração financeira. 7. ed. São Paulo: Harbra, 1997.

Princípios de administração financeira. São Paulo: Pearson Addison Wesley, 2004.

HARRIS, F. W. How many parts to make at once. Operations Research, vol. 38, n. 6, 1990.

KUNIGAMI, F. J.; OSÓRIO, W. R. Gestão no controle de estoque: estudo de caso em montadora automobilística. Revista Gestão Industrial, submetido 2009.

LEVY, M.; WEITZ, B. A. Administração de varejo. Trad. Erika Suzuki, 3. ed. São Paulo: Atlas, 2000.

MARTINS, P. G.; ALT, P. R. C. Administração de materiais e recursos patrimoniais. 2. ed. São Paulo: Saraiva, 2006. 
MARTINS, P. G.; LAUGENI, F. P. Administração da produção. São Paulo: Saraiva, 2000.

POZO, H. Administração de recursos materiais e patrimoniais: uma abordagem logística. São Paulo: Atlas, 2001.

SILVER, E. A.; PETERSON, R. Decision Systems for inventory management and production planning. 2.ed. New York: Wiley \& Sons, 1985.

SINDICATO DA HABITAÇÃO DO PARANÁ. SECOVI-PR. Tabelas do INPESPAR. Instituto Paranaense de Pesquisa e Desenvolvimento do Mercado Habitacional e Condominial do Paraná. Disponível em: <http//: www.secovi.hendrix.com.br> Acesso em 02 fev. 2007.

SLACK, N. Vantagem competitiva em manufatura: atingindo a competitividade nas operações industriais. 1. ed. São Paulo: Atlas, 1993.

SLACK, N.; CHAMBERS, S.; HARLAND, C.; HARRISON, A.; JOHNSTON, R. Administração de produção. Tradução: Ailton Bomfim Brandão. São Paulo: Atlas, 1997.

SOUSA, M. G. de. Lote econômico de compra: uma análise detalhada (2007). Disponível em: $<$ http//:www.administradores.com.br/producao_academica/lote_economico_de_compra_uma_analise _detalhada/496 /> Acesso em 12 jun. 2008.

VALLUE added products. Canadá Wood. Produits de Bois canadien. Disponível em: <http://www.canadawood.info/en/products> Acesso em: 12 dez.2007.

VIANA, J. J. Administração de materiais: um enfoque prático. São Paulo: Atlas, 2000.

WANKE. P. Tendências da gestão de estoques em organizações de saúde. Centro de Estudos Logísticos. COPPEAD/UFRJ. Rio de Janeiro, 2004. Disponível em <http:// www.centrodelogistica.com.br/new/fs.busca.htmr_art_saude.htm> Acesso em: 08 ago.2007.

WANKE, P.; FLEURY, P. F. O paradigma do ressuprimento enxuto: armadilha na gestão do fluxo de materiais entre elos da cadeia de suprimentos. Disponível em: <htpp//: www.anpad.org.br/enanpad/1999 /dwn/enanpad1999.ols-03.pdf> Acesso em 01 jun. 2008. 